\title{
Early recovery after surgery protocol in orthognathic surgery: a randomized, blind clinical study
}

\author{
Zilane Silva Barbosa de \\ OLIVEIRA $^{(a)}$ \\ Marcelo Leite Machado da \\ SILVEIRA(b) iD \\ Petrus Pereira GOMES(b) \\ José Sandro Pereira da SILVA(b) \\ Adriano Rocha GERMANO(b) iD \\ (a) Universidade Potiguar - UnP, Department of \\ Speech Therapy, Natal, RN, Brazil. \\ (b) Universidade Federal do Rio Grande do \\ Norte - UFRN, Departtment of Oral and \\ Maxillofacial Surgery, Natal, RN, Brazil.
}

Declaration of Interests: The authors certify that they have no commercial or associative interest that represents a conflict of interest in connection with the manuscript.

Corresponding Author:

Adriano Rocha Germano,

Email: adrianogermanoufrn@yahoo.com.br

htrps://doi.org/10.1590/1807-3107bor-2021.vol35.0087

Submitted: May 11, 2019

Accepted for publication: January 21, 2021

Last revision: March 1, 2021

\begin{abstract}
A randomized, blind and prospective clinical trial was conducted to compare two clinical rehabilitation protocols in patients submitted to orthognathic surgery, during the first 60 days after surgery. Pain, edema, mandibular movement, masticatory efficiency and quality of life were evaluated. Nineteen (19) patients were separated into control and experimental groups. The control group consisted of 10 patients followed by oral and maxillofacial surgeons and submitted to a rehabilitation protocol that involved active and passive mouth opening exercises. The experimental group had 9 patients and followed the surgeons' protocol, in addition to an Early Recovery After Surgery (ERAS) protocol performed by speech therapists, and involving specific motricity exercises and lymphatic drainage. The Student's t-test was applied to compare the results, and the Fisher's exact test of independence, to analyze the quality of life and the masticatory efficiency variables. The statistical significance was set at $5 \%(p<0.05)$ for all the tests. The results showed that the ERAS protocol made a positive difference in pain perception in the first 14 days. However, it did not improve the other variables. Although many variables showed no significant difference, it was concluded that the surgeons can delegate patient rehabilitation to qualified professionals, so that they can optimize their postoperative clinical time.
\end{abstract}

Keywords: Orthognathic Surgery; Surgery, Oral; Mastication; Prospective Studies; Treatment Outcome.

\section{Introduction}

Orthognathic surgery induces both morphological and functional changes. ${ }^{1}$ Thus, the integration of a multiprofessional team becomes a practically required reality. In addition to oral and maxillofacial surgeons (OMS) and orthodontists, such specialists as physiotherapists, psychologists and speech therapists, also contribute to securing treatment success. ${ }^{2}$

As orofacial motricity specialists, speech therapists contribute to restoring stomatognathic functions in patients submitted to orthognathic surgery. ${ }^{3}$ Many of these patients do not receive myofunctional therapies by a professional who obtained specific training in this field, although specialized training must be held as basic to the stabilization of the orofacial complex. It is usually the responsibility of the oral and 
maxillofacial surgeon to achieve this stabilization. ${ }^{3,4}$ Other considerations that must be borne in mind are the shortage of clinical trials in the field of speech therapy, ${ }^{5}$ and the sparce knowledge of the muscular effects of the exercises used with patients undergoing orthognathic surgery. There is a pressing need to acquire a greater scientific body of evidence before a clinical protocol can be standardized. ${ }^{6}$

In the perspective of Enhanced (or Early) Recovery after Surgery (ERAS), the scientific literature is scarce regarding the evaluation of a therapeutic program in the immediate postoperative period of orthognathic surgery, and must be broadened with further research in this field.

The purpose of this study was to compare pain, edema, mandibular movements, masticatory efficiency, and quality of life in patients submitted to orthognathic surgery, in the first 60 postoperative days, using 2 different clinical protocols for myofunctional rehabilitation.

\section{Methodology}

A randomized, blind and prospective clinical trial was conducted to compare two postoperative rehabilitation protocols in patients submitted to orthognathic surgery. Variables such as pain, edema, mandibular movements, masticatory efficiency, and quality of life were evaluated. Nineteen (19) patients were allocated into experimental and control groups. The experimental group was formed by 9 patients who followed a postoperative rehabilitation protocol set by the OMS, in addition to the ERAS protocol assisted by speech therapists (Protocol 1). In this protocol, patients were assisted by two speech therapists trained and calibrated by a blinded researcher. The control group consisted of 10 patients, and was monitored exclusively by the OMS (Protocol 2). Both protocols are described in Table 1.

Randomization was performed by Microsoft Excel®, using the randomization tool of the software program. An independent collaborator was responsible for generating the allocation sequence, and communicating the ERAS protocol to be set up for the surgeons and speech therapists. The main researcher, responsible for data collection, was blinded to the protocol received by the patients.

The authors adopted the sample size based on a similar study, because there was insufficient data in the current literature to make a meaningful sample size estimate for their statistical model. ${ }^{6}$ The sample size was estimated based on available, but incomplete information. After the study commenced, the parameter estimates for the initial sample size were validated for the data collected. Based on the statistical analysis implemented, an $84 \%$ power was obtained for the variables analyzed during the evaluation period. Thus, the initial sample size met the requirements needed to evaluate the hypothesis presented. A convenience sample of 23 patients was enrolled in the study, only 19 of whom completed it. The 4 patients excluded missed one or more follow-up sessions (Figure 1).

The patients selected for the study included those who presented dentofacial deformities and needed orthognathic surgery, and those and who were admitted to the oral and maxillofacial program of the Federal University of Rio Grande do Norte between November

Table 1. Myofunction rehabilitation protocols.

\begin{tabular}{|c|c|}
\hline Protocol 1 & Protocol 2 \\
\hline $\begin{array}{l}\text { 1. Four sessions in the first week post-op (S1 to S4) - two weekly sessions } \\
\text { starting in the second week, and ending in the fourth week (S5 to S10). }\end{array}$ & $\begin{array}{l}\text { 1. First to } 8^{\text {th }} \text { week post-op - weekly instructions for active } \\
\text { mandibular movement. Patients were instructed to perform } \\
\text { mandibular movement exercises at home. }\end{array}$ \\
\hline $\begin{array}{l}\text { 2. All sessions (S1 to S10) - provide instructions about therapy objectives } \\
\text { and myofunctional and stomatognathic functions; lymphatic drainage; } \\
\text { lip and neck muscular active movement exercises with passive intraoral } \\
\text { manipulation and salivary and extraoral sensitivity control. }\end{array}$ & $\begin{array}{l}\text { 2. Fourth to } 8^{\text {th }} \text { week post-op - passive mouth opening exercises } \\
\text { using wooden tongue depressor. }\end{array}$ \\
\hline 3. From S2 to S10 - active and passive mandible manipulation. & $\begin{array}{l}\text { 3. Every week - nutritional orientation -intake of liquids in the } \\
\text { first ten days, pasty food from the } 10^{\text {th }} \text { to the } 45^{\text {th }} \text { day, and solids } \\
\text { allowed after the } 45^{\text {th }} \text { day. }\end{array}$ \\
\hline
\end{tabular}




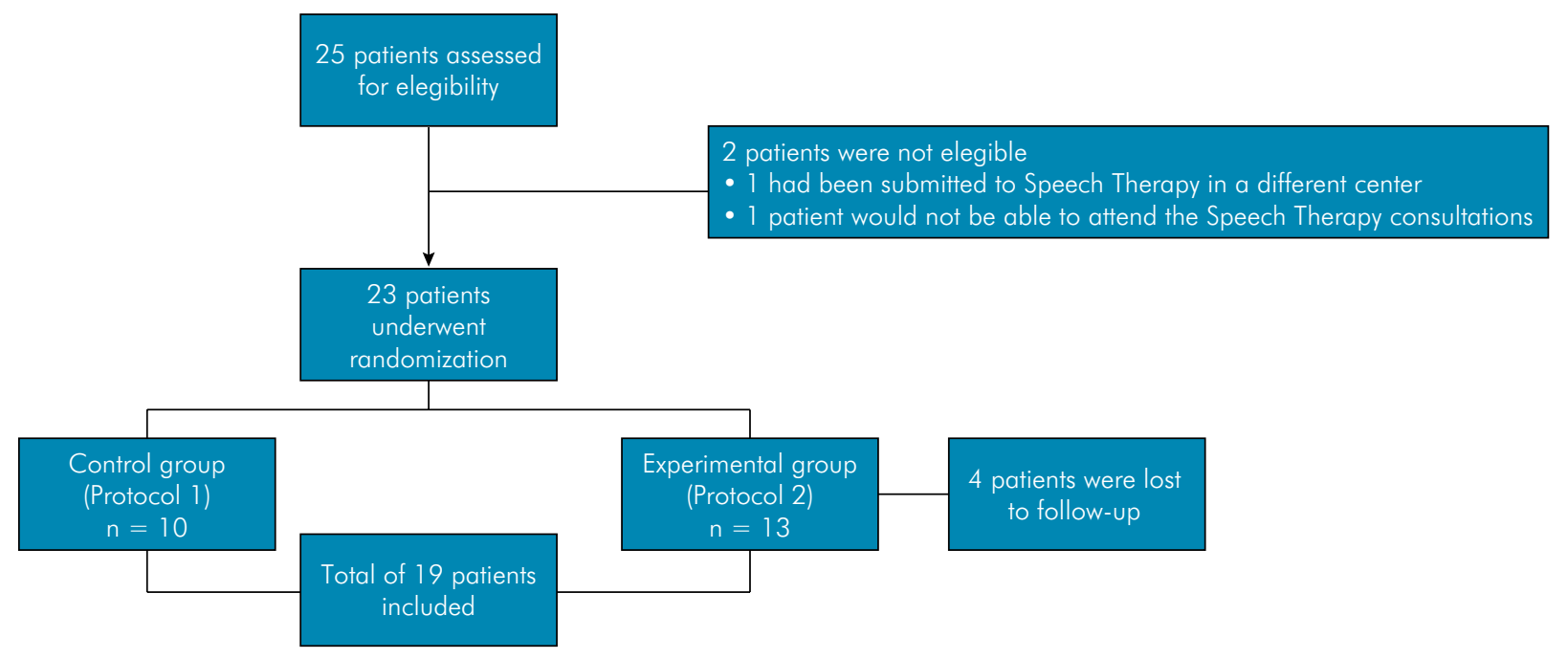

Figure 1. Patient randomization diagram.

2013 and December 2014. Inclusion criteria consisted of individuals aged 16 to 50 years, submitted to mandibular orthognathic surgery, whether or not associated to maxillary surgery; ASA I and II patients ${ }^{7}$ who had not performed any preoperative speech therapy guidance or procedure; and patients who duly completed their myofunctional rehabilitation protocols. The exclusion criteria comprised patients needing a new surgical procedure; those with a neurological deficit of central and/or cognitive origin, which kept them from undergoing any stage of the research; those with a dentofacial deformity associated with facial trauma; those with a contraindication to the use of postoperative medication; and those who had undergone both orthognathic and joint surgery. Patients who did not wish to participate in the study, or who did not fulfill the protocol schedule were also excluded.

Informed written consent was obtained through informed consent forms, as determined by the National Health Council (Resolution 196/96) for research on human beings. The study was submitted to the Research Ethics Committee of the Onofre Lopes University Hospital of the Federal University of Rio Grande do Norte, approved and registered under number 662.136 .

The osteotomies performed, the length of hospital stay, and the medications used were all standardized for each patient, so as to reduce possible variables that could alter the importance of the rehabilitation protocol.
In Protocol 1 (experimental group), the patients were followed by speech therapists, and had their first consultation in the first week post-op. They had 4 sessions of speech therapy in the first week, and 2 sessions a week from the second to the fourth week, for a total of 10 sessions. The speech therapy sessions lasted 30 minutes. Lymphatic drainage was performed from the first to the tenth session, during the first 20 minutes of consultation, using Vodder's manual method. The other 10 minutes of the consultation were dedicated to exercises. Patients were submitted to labial protrusion and retrusion exercises starting at the first session. They also received instructions on how to perform these exercises at home 3 to 5 times a day in 3 sequences of 10 movements. In the fourth session, mouth opening exercises were initiated and patients were instructed to repeat them at home using the same pattern as the lip exercises cited before. In addition to the speech therapy sessions, patients would also meet with the OMS, and followed the surgeons' protocol.

The surgeons' protocol refers to the myofunctional rehabilitation protocol commonly used in the Department of Oral and Maxillofacial Surgery of the Federal University of Rio Grande do Norte (RN, Brazil) for patients submitted to orthognathic surgery. This protocol was applied in both control and experimental groups, and was the only rehabilitation protocol used for patients in the control group (Protocol 2). In this 
protocol, patients received a weekly consultation during the first two months after surgery, and were instructed to move their jaw actively starting the first week post-op. They were instructed to perform mouth opening exercises, mandibular lateral movements and protrusion at home 3 times a day, for 20-minute periods. These exercises had to be done actively in order to provide early mandibular mobility. Thirty days after surgery, the patients were instructed to perform passive exercises with wooden spatulas to gain better mouth opening. These exercises were done during the consultation, and patients were instructed to repeat them at home 3 times a day up to the $8^{\text {th }}$ postoperative week. The spatulas were designed to enable a mouth opening of at least $22 \mathrm{~mm}$, and patients were encouraged to improve the mark by adding more spatulas during the sessions, to ultimately gain a wider mouth span after each session.

Patients were released to return to orthodontic treatment two months post-surgery in both groups. They were also given elastic therapy to achieve better occlusion when needed. Rubber bands were usually introduced in the first week, and maintained up to 30 days post-surgery. The patients were advised to remove the bands to perform the physiotherapy exercises after the second week post-op.

The evaluations of pain, edema and mandibular movements were performed in 2, 4, 7, 14, 30 and 60 postoperative days, and were measured solely by the main researcher, who was blinded to the individual's group. The masticatory efficiency and quality of life were evaluated initially at 60 postoperative days, and the questionnaire on quality of life was applied at this time, and again in the $6^{\text {th }}$ postoperative month.

The Visual Analogue Scale (VAS) was used to evaluate the pain. The VAS consists of a horizontal line measuring $10 \mathrm{~cm}$, marked with " 0 " (absence of pain) at one end, and " 10 " (worst possible pain) at the other. The patient defines what point on the scale best represents the pain intensity, at each evaluation.

The distances from the facial reference points were measured by linear measurements to evaluate the facial volume modification, as described by Neupert et al. ${ }^{8}$ Measurements of linear distances were made between the angle of the mandible and the following points: tragus, nasal wing, outer corner of the eye, labial commissure and chin. The points were marked with a dermographic pen, and re-marked at each subsequent measurement (Figure 2 - A, B). The first demarcation was performed before surgery, and was reinforced in the trans- and postoperative periods. The linear distances from the mandibular point to the other points were measured with a 3-0 nylon suture wire, with the patients seated and looking forward, in maximum dental intercuspation and with their lips at rest.

Mouth opening was measured by the interincisal distance using a digital caliper (WESTERN-ref DC-6), taking the incisal points of the upper and lower right central incisors as the points of reference; measurements were made in mm (Figure 3A). Laterality movements, to the right and left were also measured (Figure 3B). All of these values were quantified in $\mathrm{mm}$ and classified using the criteria described in the MBGR protocol ${ }^{9}$, at the same time intervals as those already described for the other variables.

The protocol proposed by Whitaker et al. ${ }^{10}$ was used to standardize the evaluation of masticatory efficiency, made by patients 60 days after surgery. This protocol uses almonds as a test food, and a sieving system with sieves of various meshes to filter the crushed fragments during mastication (Figures 4 and 5). Accordingly, the masticatory efficiency could be classified as very good, good, regular, bad or very bad, based on the size and quantity of crushed fragments produced by the patients and retained by the sieves.
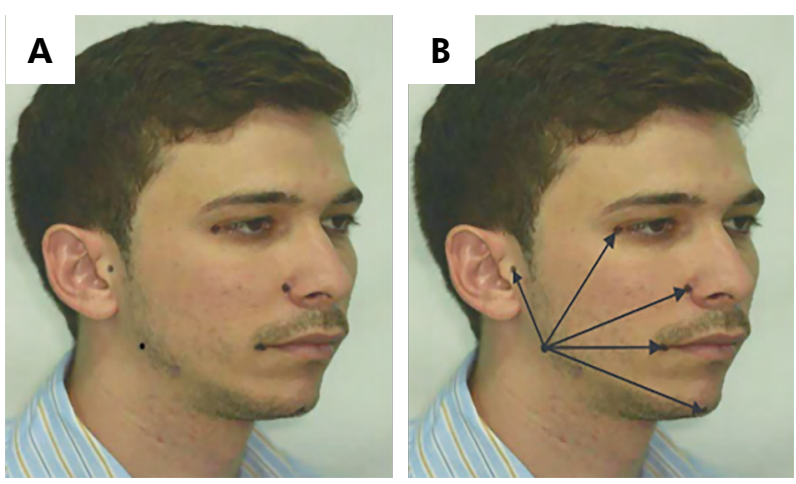

Figure 2. A - Lateral view of craniofacial landmarks (mandibular angle, tragus, nasal wing, outer corner of the eye, labial commissure and chin). B - Lateral view of linear measurements taken from the mandibular angle to other facial landmarks. 

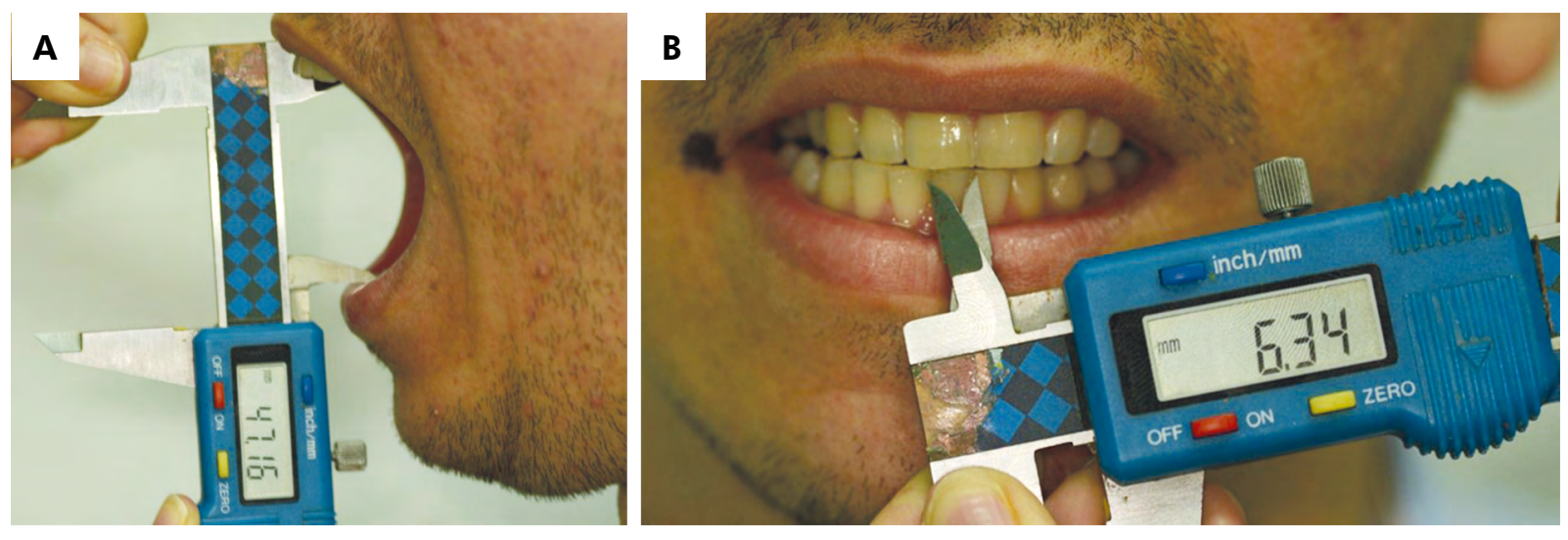

Figure 3. Mandibular movement measurements made with a standard caliper. A - Mouth opening. B - Lateral movement.

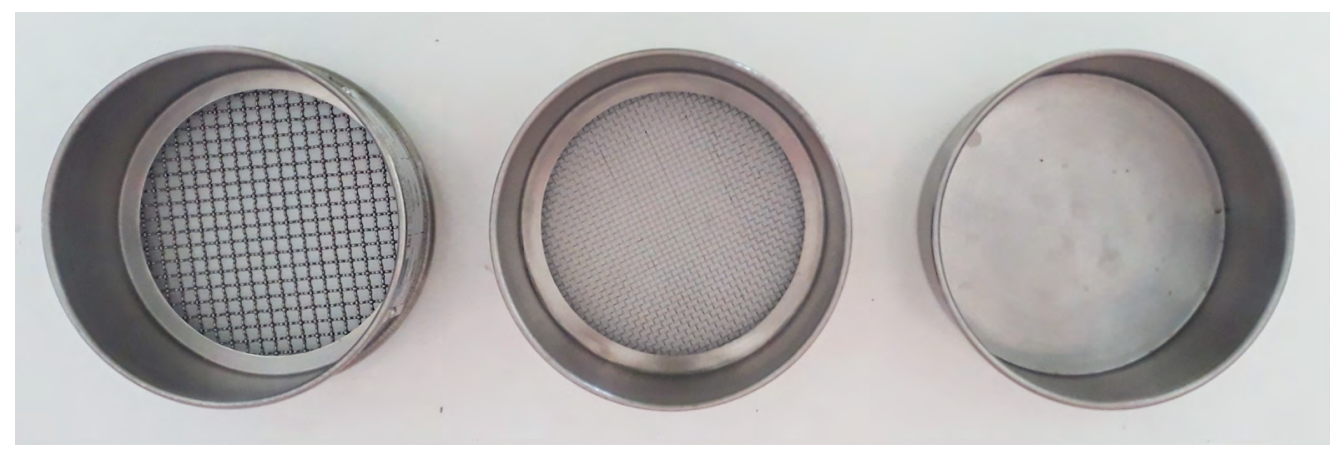

Figure 4. Sieving system used to filter the almonds after the masticatory efficiency test. Observe the sieves of several different meshes.

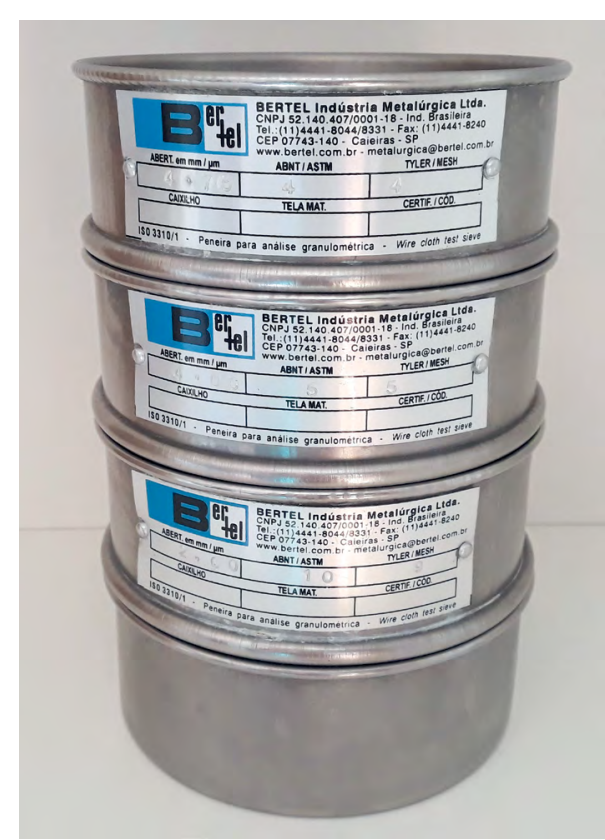

Figure 5. Sieving system vertically disposed for testing. The sieve with larger mesh spaces was placed higher, and that with smaller mesh spaces, at the bottom.
The impact of the oral condition on quality of life was measured using the OHIP-14, 11 days post-surgery in the form of an interview. This questionnaire covers seven dimensions, corresponding to functional limitation, physical pain, psychological discomfort, social disadvantage, and physical, psychological and social disabilities. Each item has a score, and the sum of the points are tallied to produce an overall score. The lower the value of the score, the lower the negative impact of orthognathic surgery on quality of life.

\section{Statistical analysis}

The Kolmogorov-Smirnov test was the first analysis made to test for normal distribution, based on which either parametric or non-parametric tests were applied. A Student's t-test was applied to compare the improvements in the parameters for the protocols regarding each variable, and the different evaluation moments. Fisher's exact test of independence was applied to analyze the quality of life variable, and 
the masticatory efficiency variable. The statistical significance was set at $5 \%(\mathrm{p}<0.05)$ for all the tests. The analysis of variance (ANOVA) for repeated measures was used to evaluate possible changes in pain, edema and mandibular movement over time $(2,4,7,14,30$ and 60 days). Tukey's HSD post hoc test was used to identify the specific differences in the variables, and applied when the p-values found were higher than the established statistical significance criterion $(\mathrm{p}<0.05)$.

\section{Results}

The analysis of variance (ANOVA) revealed that the pain evaluated during the first 14 days of follow-up was positively influenced by the ERAS protocol (Protocol 1), and no statistically significant difference was observed after 60 days of follow-up. This group presented lower values during this period, which means less pain than the control group during the first two weeks of follow-up. Nevertheless, the pain perception was statistically significant only in relation to the evolution of time, considering that both groups showed improvement in pain perception over time (Table 2).

Table 3 shows the edema measured in $\mathrm{cm}$, whereas Table 4 shows the reduction in the edema in percentage terms in the first 48 hours up to 60 days postoperatively by region, and in the face as a whole. The results show a statistically significant reduction in edema in relation to the time at which the two

Table 2. VAS pain measurement, in $\mathrm{cm}$, and mean and standard deviation during the 60 post-operative days: ERAS group (Protocol 1) and control group (Protocol 2).

\begin{tabular}{lccc}
\hline \multirow{2}{*}{ Period } & \multicolumn{2}{c}{ VAS } & p-value \\
\cline { 2 - 3 } & Protocol 1 & Protocol 2 & \\
\hline 48 hours & $1.99 \pm 1.95$ & $2.61 \pm 2.08$ & $0.065^{\circ}$ \\
96 hours & $1.57 \pm 1.66$ & $2.47 \pm 2.32$ & $0.010^{\mathrm{b}}$ \\
7 days & $1.01 \pm 1.24$ & $1.68 \pm 1.9$ & $0.971^{\mathrm{c}}$ \\
14 days & $0.68 \pm 1.19$ & $1.48 \pm 1.42$ & \\
30 days & $0.86 \pm 1.57$ & $0.84 \pm 1.7$ & \\
60 days & $0.29 \pm 0.73$ & $0.82 \pm 1.41$ & \\
\hline
\end{tabular}

Mean \pm Standard deviation. ${ }^{a} \mathrm{p}$-value for treatment effect using analysis of variance (ANOVA); ${ }^{b} p$-value for time influence using analysis of variance (ANOVA); ${ }^{c} p$-value for the effect of treatment vs. time using analysis of variance (ANOVA). groups were compared $(\mathrm{p}<0.05)$. In relation to the protocol received, the only a statistically significant reduction in the edema was observed in the linear measurement between the tragus and the mandibular angle, in the group that received follow-up with speech therapists (Protocol 1).

Mandibular movement (Table 5), masticatory efficiency (Table 6) and quality of life assessed with the OHIP-14 questionnaire (Table 7) showed no statistical difference between the protocols. Nevertheless, Fisher's test showed that masticatory efficiency (ME) in the group that performed speech therapy was distributed equally between regular and very bad, whereas the control group had a predominance of very bad ME. Both protocols showed a statistically significant difference regarding the time factor, when the mandibular movement was assessed.

\section{Discussion}

Previous articles published in the literature have suggested that more intensive postoperative care is better for patients undergoing facial surgery than more traditional rehabilitation..$^{12,13}$ According to the results of this study, speech therapy rehabilitation influenced the outcome positively, thus minimizing pain and discomfort in the first 14 postoperative days, in which higher pain intensity was expected; however, this finding was no longer evidenced after 14 days (Table 2).

Rehabilitation with speech therapy may have contributed to decreasing the patients' anxiety, and reinforcing the patients' confidence. The more satisfactory results for this group were reflected by the decrease in pain perception, and the effect on the emotional component. Another factor to be borne in mind is that the massage therapy may have had an effect on the facial musculature, owing to the release of endorphins and enkephalins, and thus enabling a more significant analgesic effect at this stage. These effects, whether separately or combined, may have influenced the best pain response for the ERAS group in the first 14 days (Table 2).

It has been previously reported that time exerts a substantial influence on pain reduction. ${ }^{14,15}$ At 14 days, 


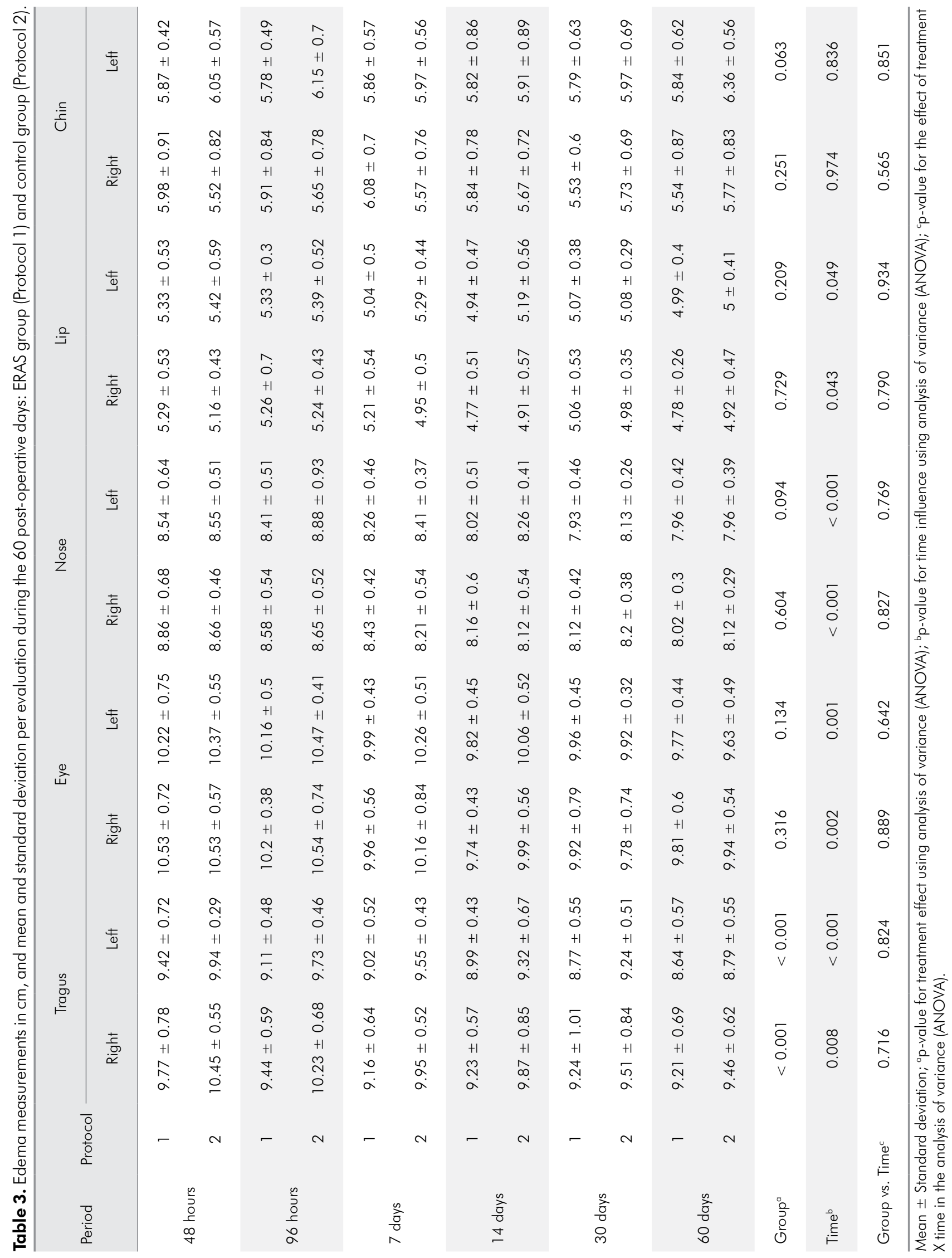


Table 4. Comparison of edema reduction in percentage and between the two groups: ERAS group (Protocol 1) and control group (Protocol 2).

\begin{tabular}{lccc}
\hline \multirow{2}{*}{ Variable } & \multicolumn{2}{c}{ Edema reduction (\%) } & p-value \\
\cline { 2 - 3 } & Protocol 1 & Protocol 2 & \\
\hline Tragus & $7.15 \pm 2.00$ & $10.45 \pm 3.67$ & 0.029 \\
Eye & $7.54 \pm 5.76$ & $8.4 \pm 2.83$ & 0.694 \\
Nose & $8.74 \pm 5.41$ & $11.19 \pm 7.3$ & 0.423 \\
Lip & $10.4 \pm 7.49$ & $10.57 \pm 8.41$ & 0.964 \\
Chin & $6.17 \pm 11.09$ & $-1.26 \pm 10.47$ & 0.152 \\
Face & $8.00 \pm 4.22$ & $7.87 \pm 4.31$ & 0.947 \\
\hline
\end{tabular}

Mean \pm Standard deviation. *Student's t-test.

Table 5. Mandibular movement measurements in $\mathrm{mm}$, mean and standard deviation - ERAS group (Protocol 1) and control group (Protocol 2).

\begin{tabular}{|c|c|c|c|c|}
\hline \multirow{2}{*}{ Period } & \multirow{2}{*}{ Group } & \multirow{2}{*}{$\begin{array}{l}\text { Mouth } \\
\text { opening } \\
(\mathrm{mm})\end{array}$} & \multicolumn{2}{|c|}{ Laterality (mm) } \\
\hline & & & Right & Left \\
\hline \multirow{2}{*}{48 hours } & Protocol 1 & $7.95 \pm 5.3$ & $1.36 \pm 1.72$ & $1.34 \pm 1.6$ \\
\hline & Protocol 2 & $9.28 \pm 6.69$ & $0.96 \pm 1.33$ & $0.84 \pm 1.52$ \\
\hline \multirow{2}{*}{96 hours } & Protocol 1 & $13.81 \pm 4.43$ & $1.81 \pm 2.22$ & $2.13 \pm 2.61$ \\
\hline & Protocol 2 & $11.18 \pm 4.57$ & $1.76 \pm 2.43$ & $1.05 \pm 1.28$ \\
\hline \multirow{2}{*}{7 days } & Protocol 1 & $14.4 \pm 5.08$ & $1.55 \pm 1.98$ & $2.14 \pm 2.19$ \\
\hline & Protocol 2 & $13.2 \pm 5.11$ & $2.11 \pm 2.35$ & $2.03 \pm 1.73$ \\
\hline \multirow{2}{*}{14 days } & Protocol 1 & $16.66 \pm 5.22$ & $2.6 \pm 2.29$ & $3.93 \pm 1.98$ \\
\hline & Protocol 2 & $13.44 \pm 5.11$ & $2.63 \pm 2.37$ & $2.58 \pm 2.44$ \\
\hline \multirow{2}{*}{30 days } & Protocol 1 & $21.62 \pm 5.17$ & $5.54 \pm 2.92$ & $5.07 \pm 2.53$ \\
\hline & Protocol 2 & $22.27 \pm 7.01$ & $5.03 \pm 2.92$ & $3.65 \pm 2.32$ \\
\hline \multirow{2}{*}{60 days } & Protocol 1 & $33.01 \pm 8.34$ & $6.06 \pm 3.14$ & $5.87 \pm 3.29$ \\
\hline & Protocol 2 & $32.93 \pm 10.52$ & $6.19 \pm 2.99$ & $5.65 \pm 2.76$ \\
\hline Group $^{a}$ & & 0.474 & 0.934 & 0.068 \\
\hline Time $^{b}$ & & $<0.001$ & $<0.001$ & $<0.001$ \\
\hline Group vs. & Time $^{c}$ & 0.860 & 0.988 & 0.906 \\
\hline
\end{tabular}

Mean \pm Standard deviation. ${ }^{a} \mathrm{p}$-value for treatment effect using analysis of variance (ANOVA); ${ }^{b} p$-value for time influence using analysis of variance (ANOVA); $c$-value for the effect of treatment vs. time using analysis of variance (ANOVA).

Table 6. Masticatory Efficiency (ME) classification in both ERAS group (Protocol 1) and control group (Protocol 2) in the 60 th post-operative day.

\begin{tabular}{lccccc}
\hline & \multicolumn{4}{c}{ Masticatory Efficiency } & \\
\cline { 2 - 5 } Group & \multicolumn{2}{c}{ Very bad } & \multicolumn{2}{c}{ Regular } & p-value \\
\cline { 2 - 4 } & $\mathrm{n}$ & $\%$ & $\mathrm{n}$ & $\%$ & \\
\hline Protocol 1 & 4 & 50.0 & 4 & 50.0 & \multirow{2}{*}{0.630} \\
Protocol 2 & 7 & 70.0 & 3 & 30.0 & \\
\hline
\end{tabular}

Mean \pm Standard deviation. *Fisher's exact test of independence.
Table 7. Mean and standard deviation for OHIP- 14 quality of life questionnaire values for both ERAS group (Protocol 1) and control group (Protocol 2).

\begin{tabular}{lccc}
\hline \multirow{2}{*}{ Period } & \multicolumn{2}{c}{ OHIP-14 } & p-value* \\
\cline { 2 - 3 } & Protocol 1 & Protocol 2 & \\
\hline 2 months & $19.67 \pm 11.37$ & $18.3 \pm 13.16$ & 0.813 \\
6 months & $9.22 \pm 7.45$ & $11.11 \pm 14.63$ & 0.734 \\
\hline Mean \pm Standard deviation. *Student's t-test. &
\end{tabular}

Mean \pm Standard deviation. *Student's t-test.

there was a decrease in the pain sensation, with no need for analgesic medication in most cases. This probably occurred in both groups, regardless of the protocol received.

The results indicated that the edema did not decrease more rapidly during the 60 days of follow-up, in the protocol with the speech therapists (Table 3). Chung How Kau et al. also observed that the edema is greater in the first 3 days after surgery, but improves significantly over time, without related therapeutic intervention. ${ }^{16}$

Ferreira ${ }^{17}$ recommends that the speech therapist should instruct and supervise the patient in performing manual lymphatic drainage (MLD), since there is the risk that the treatment will not be performed correctly if the patient lacks follow-up. The MLD in the protocol of this study did not include the guidelines for the massages to be performed at home by the patients, a factor that could have intensified and modified the results.

In the group with speech therapy, the lack of adhesion to perform the exercises at home may have influenced the results, and should be weighed. Another aspect to consider is the effectiveness of the method of measuring the edema. This method may be faulty because the region of the mandible angle, which serves as a reference for the measurements, may undergo changes and lead to different linear measurements. ${ }^{18}$

Parameters related to mastication promote a more appropriate evaluation of its function, and may also reflect the stability of long-term postoperative results. ${ }^{6,10}$ In this study, two tests related to mastication were evaluated: mandibular movements (laterality and opening) and masticatory efficiency (Tables 5 and 6). There are several other protocols in the literature, but none have proved ideal as of yet. ${ }^{6,19,20}$ 
Both rehabilitation protocols proposed in this study were initiated in the first postoperative week, which is a distinct time period in relation to the others. ${ }^{20}$ Most researchers suggest that the mandible is involved in progressive functional exercise, ${ }^{21,22}$ and report that masticatory exercises are needed to improve masticatory efficiency, mainly in restoring muscular activity. ${ }^{19}$ However, some authors recommend that the temporary reduction in mandibular movements without therapeutic rehabilitation favors their full rehabilitation, which can occur anywhere from six months to two years. $1,15,16,17,18,19,20,21,22,23$

Although mandibular movements increased over 2 months post-surgery, both protocols had similar mean values, namely $33 \mathrm{~mm}$ for opening, and 5 to $6 \mathrm{~mm}$ for laterality (Table 5). These values are low compared with those recommended in the Genaro et al. ${ }^{9}$ protocol, namely 6 to $12 \mathrm{~mm}$ for laterality, and 40 to $55 \mathrm{~mm}$ for mouth opening. However, since the last measurement was performed at 2 months, the values may change later on, and eventually achieve normal values. ${ }^{24}$ Most patients remained in orthodontic treatment throughout the rehabilitation period, which continued to influence the results. ${ }^{26}$ In addition, the values obtained for both groups enabled both postoperative orthodontic treatment and gradual functional rehabilitation to be continued.

Although the surgeon was not the same for all the surgeries, the team belonged to the same program, and maintained the standard routine and surgery time. The study was standardized by randomizing the sample and performing bimaxillary surgeries in all the cases; this reduced the interference of this variable in the postoperative outcomes. This standardization reflects the positive aspect of this study, considering that the literature reports a difference in the rehabilitation time of mandibular mobility, according to the type of surgery performed. ${ }^{25,27}$

The ideal situation would be to evaluate masticatory efficacy at 6 months; however, this would imply that patients in the group not receiving speech therapy would continue without it. This would not be an ethical choice, because many patients need to undergo therapy to correct adapted swallows, improve lip sealing, stimulate smile symmetry, and other factors regarded as being clinical situations that speech therapy can improve better and faster. ${ }^{28,29}$

One factor that may minimize the effectiveness of the ERAS protocol is the use of postoperative elastics that limit mandibular function. In this study, they were applied only to allow free speech therapy intervention after 15 days. Only with the definitive elimination of the 30-day postoperative elastic therapy in some patients was the speech therapist able to perform rehabilitation, and adopt a more therapeutic approach, thus achieving more corrective therapy. The gradual reintroduction of solid food is also recommended during this period. ${ }^{30,31,32}$

The majority of authors recommend that follow-up for quality of life should be conducted at least 6 months post-surgery, justifying that the edema decreases during this period, thereby allowing patients better visualization and perception of esthetic modifications and facial functions when they are to effectively resume social interaction. ${ }^{33,34}$ The results did not show statistically significant differences between the groups, and evidenced positive effects in both groups (Table 7).

\section{Conclusions}

Although no statistical difference was found between the protocols, the ERAS rehabilitation protocol made a positive difference in the patient's perception of pain up to the first 14 days of follow-up.

Improvements can be made to the speech therapy protocol. For instance, the oral and maxillofacial surgeon should be able to count on speech therapists to take an active role in the patients' postoperative rehabilitation, so that the surgeon can focus attention on other issues of the surgical procedure, and thus provide these patients with the best possible treatment.

\section{Acknowledgements}

This study was submitted to the Research Ethics Committee of the Onofre Lopes University Hospital of the Federal University of Rio Grande do Norte, and obtained approval and registration under number 662.136. 
Early recovery after surgery protocol in orthognathic surgery: a randomized, blind clinical study

\section{References}

1. Ueki K, Marukawa K, Moroi A, Sotobori M, Ishihara Y, Iguchi R, et al. The time-course change in the lip closing force in Class III malocclusion after orthognathic surgery. J Craniomaxillofac Surg. 2014 Sep;42(6):896-900. https://doi.org/10.1016/i.jcms.2014.01.007

2. Gallerano G, Ruoppolo G, Silvestri A. Myofunctional and speech rehabilitation after orthodontic-surgical treatment of dento-maxillofacial dysgnathia. Prog Orthod. 2012 May;13(1):57-68. https://doi.org/10.1016/i.pio.2011.08.002

3. Felício CM, Couto GA, Ferreira CLP, Mestriner Junior W. Reliability of masticatory efficiency with beads and correlation with the muscle activity. Pró-Fono R Atual Cient 2008;20(4):225-30. https://doi.org/10.1590/S0104-56872008000400004

4. Ladeira PR, Alonso N. Current state and future perspectives of craniofacial surgery research: systematic review. Rev Bras Cir Plást. 2013;28(2):301-6. https://doi.org/10.1590/S1983-51752013000200023

5. Ferreira TS, Mangilli LD, Sassi FC, Fortunato-Tavares T, Limongi SC, Andrade CR. Speech and myofunctional exercise physiology: a critical review of the literature. J Soc Bras Fonoaudiol. 2011 Sep;23(3):288-96. https://doi.org/10.1590/S2179-64912011000300017

6. Mangilli LD. Programa de avaliação e tratamento fonoaudiológico para a reabilitação da função mastigatória de indivíduos submetidos à cirurgia ortognática por deformidade dentofacial [doctor thesis]. São Paulo: Faculdade de Medicina; 2012.

7. Fitz-Henry J. The ASA classification and peri-operative risk. Ann R Coll Surg Engl. 2011 Apr;93(3):185-7. https://doi.org/10.1308/rcsann.2011.93.3.185a

8. Neupert EA 3rd, Lee JW, Philput CB, Gordon JR. Evaluation of dexamethasone for reduction of postsurgical sequelae of third molar removal. J Oral Maxillofac Surg. 1992 Nov;50(11):1177-82. https://doi.org/10.1016/0278-2391(92)90149-T

9. Genaro KF, Félix BG, Rehder MI, Marchesan IQ. Orofacial myofunctional evaluation - MBGR protocol. Rev CEFAC. 2009;11(2):237-55. https://doi.org/10.1590/S1516-18462009000200009

10. Whitaker ME, Trindade Junior AS, Genaro KF. Proposta de protocolo da avaliação clínica da função mastigatória. Rev CEFAC. 2009;11(13 suppl 3):311-23. https://doi.org/10.1590/S1516-18462009005000030

11. Sousa PC, Mendes FM, Imparato JC, Ardenghi TM. Differences in responses to the Oral Health Impact Profile (OHIP14) used as a questionnaire or in an interview. Braz Oral Res. 2009 Oct-Dec;23(4):358-64. https://doi.org/10.1590/S1806-83242009000400002

12. Mottura AA. Face lift postoperative recovery. Aesthetic Plast Surg. 2002 May-Jun;26(3):172-80. https://doi.org/10.1007/s00266-001-0029-3

13. Nicodemo D, Pereira MD, Ferreira LM. Cirurgia ortognática: abordagem psicossocial em pacientes Classe III de Angle submetidos à correção cirúrgica da deformidade dentofacial. Rev Dent Press Ortodon Ortop Facial. 2007;12(5):46-54 https://doi.org/10.1590/S1415-54192007000500007

14. Szolnoky G, Szendi-Horváth K, Seres L, Boda K, Kemény L. Manual lymph drainage efficiently reduces postoperative facial swelling and discomfort after removal of impacted after removal of impacted third molars. Lymphology. 2007 Sep;40(3):138-42.

15. Gasperini G, Siqueira ICR, Rezende Costa LR. Does low-level laser therapy decrease swelling and pain resulting from orthognathic surgery? Int J Oral Maxillofac Surg. 2014 Jul;43(7):868-73. https://doi.org/10.1016/i.ijom.2014.02.015

16. Kau CH, Cronin AJ, Richmond S. A three-dimensional evaluation of postoperative swelling following orthognathic surgery at 6 months. Plast Reconstr Surg. 2007 Jun;119(7):2192-9. https://doi.org/10.1097/01.prs.0000260707.99001.79

17. Ferreira TR. Drenagem linfática manual no pós-operatório de enxerto ósseo alveolar: uma nova abordagem para a redução do edema facial [dissertation]. Bauru: Hospital de Reabilitação de Anomalias Crniofaciais; 2010.

18. Laureano Filho JR, Camargo IB, Firmo AC, Silva ED. Evaluation of laser therapy in edema, pain and trismus reduction after removal of inferior third molars: preliminary results. Rev Cir Traumatol Buco-Maxilo-Fac. 2008 Jan.-Mar.;8(1):47-56.

19. Kato K, Kobayashi T, Kato Y, Takata Y, Yoshizawa M, Saito C. Changes in masticatory functions after surgical orthognathic treatment in patients with jaw deformities: efficacy of masticatory exercise using chewing gum. J Oral Maxillofac Surg Med Pathol. 2012;24(3):147-51. https://doi.org/10.1016/i.ajoms.2011.07.009

20. Teng TT, Ko EW, Huang CS, Chen YR. The effect of early physiotherapy on the recovery of mandibular function after orthognathic surgery for Class III correction: part I_-jaw-motion analysis. J Craniomaxillofac Surg. 2015 Jan;43(1):131-7. https://doi.org/10.1016/j.jcms.2014.10.025

21. Trawitzki LV, Silva JB, Regalo SC, Mello-Filho FV. Effect of class II and class III dentofacial deformities under orthodontic treatment on maximal isometric bite force. Arch Oral Biol. 2011 Oct;56(10):972-6. https://doi.org/10.1016/i.archoralbio.2011.02.018

22. Ko EW, Teng TT, Huang CS, Chen YR. The effect of early physiotherapy on the recovery of mandibular function after orthognathic surgery for class III correction. Part II: electromyographic activity of masticatory muscles. J Craniomaxillofac Surg. 2015 Jan;43(1):138-43. https://doi.org/10.1016/j.jcms.2014.10.028

23. Nakata $Y$, Ueda HM, Kato M, Tabe H, Shikata-Wakisaka N, Matsumoto E, et al. Changes in stomatognathic function induced by orthognathic surgery in patients with mandibular prognathism. J Oral Maxillofac Surg. 2007 Mar;65(3):444-51 https://doi.org/10.1016/j.joms.2005.12.071 
24. Sforza C, Ugolini A, Rocchetta D, Galante D, Mapelli A, Giannì AB. Mandibular kinematics after orthognathic surgical treatment a pilot study. Br J Oral Maxillofac Surg. 2010 Mar;48(2):110-4. https://doi.org/10.1016/i.bjoms.2008.09.002

25. Kim DS, Huh KH, Lee SS, Heo MS, Choi SC, Hwang SJ, et al. The relationship between the changes in three-dimensional facial morphology and mandibular movement after orthognathic surgery. J Craniomaxillofac Surg. 2013 Oct;41(7):686-93. https://doi.org/10.1016/i.jcms.2013.01.011

26. Farronato G, Giannini L, Galbiati G, Stabilini SA, Maspero C. Orthodontic-surgical treatment: neuromuscular evaluation in open and deep skeletal bite patients. Prog Orthod. 2013 Oct;14(1):41. https://doi.org/10.1186/2196-1042-14-41

27. Pereira JB. Deformidades dentofaciais: caracterização das funções estomatognáticas e disfunções temporomandibulares pré e pós cirurgia ortognática e reabilitação fonoaudiológica [dissertation]. Rio de Janeiro: Universidade Veiga de Almeida; 2009.

28. Bianchini EM. Mastigação e ATM. In: Marchesan IQ, editor. Fundamentos em fonoaudiologia. São Paulo: Guanabara- Koogan; 1998.

29. Cattoni DM. Alterações da mastigação e deglutição. In: Ferreira LP, editor. Fonoaudiologia. São Paulo: Roca; 2004. p. $277-91$.

30. Aléssio CV, Mezzomo CR, Körbes D. The myofunctional treatment in class III patients recommended for orthognathic surgery. Arq Odontol. 2007;43(3):102-10.

31. Pacheco VS. Orthognathic surgery: a speech therapist approach. Rev CEFAC. 2000;2(2):38-44.

32. Campiotto AR, Freitas RR. Fonoaudiologia nas cirurgias ortognáticas. In: Lopes Filho O, editor. Fonoaudiologia. Ribeirão Preto: Artmed; 2005.

33. Carvalho SC, Martins EJ, Barbosa MR. Psychosocial variables associated with orthognathic surgery: a systematic literature review. Psicol Reflex Crit. 2012;25(3):477-90. https://doi.org/10.1590/S0102-79722012000300007

34. Silva ACA, Carvalho RA, Santos TS, Rocha NS, Gomes AC, Silva EDO. Evaluation of life quality of patients submitted to orthognathic surgery. Dental Press J Orthod. 2013 Sep-Oct;18(5):107-14. https://doi.org/10.1590/S2176-94512013000500018 